 \\ UF $\mid$ FLORIDA

\author{
UF
}

\section{Soft Rush (Juncus effusus) Biology and Control in Pastures 1}

\section{Brent Sellers, Jason Ferrell, and Reyna Speckmann²}

Soft rush, often called bull rush, is a clump-forming perennial plant that frequently infests low-lying areas in Florida pastures and is typically found in pastures that are seasonally wet with alternating wet and dry seasons (Figure 1). Soft rush does not generally grow where water is present year-round, but is often present along the perimeters of ponds, lakes, streams, and canals.

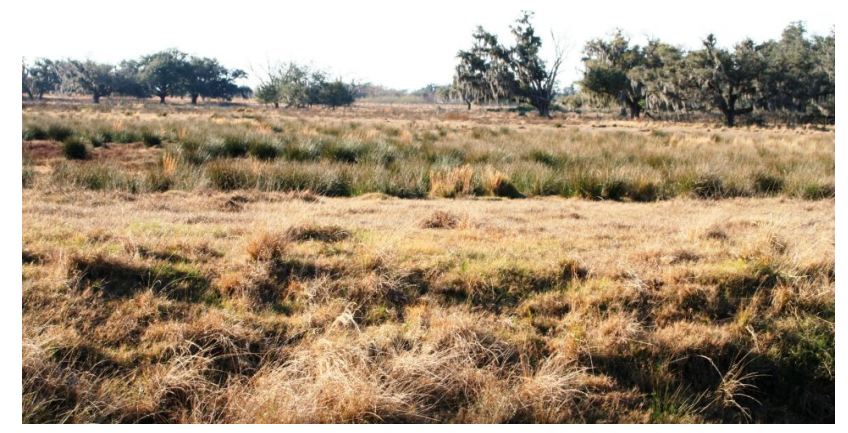

Figure 1. Soft rush commonly grows in low-lying areas in pastures. During the dry season, these areas can be treated to control soft rush. Credits: Brent Sellers

While cattle do not readily graze soft rush, they have been observed to graze it when other forage is severely limited. Generally, however, cattle avoid areas of soft rush. As a result, the presence of soft rush tends to limit the area available to cattle for grazing. Cattle avoidance of soft rush is often evidenced by the signs of trampling around individual soft rush plants (Figure 2).

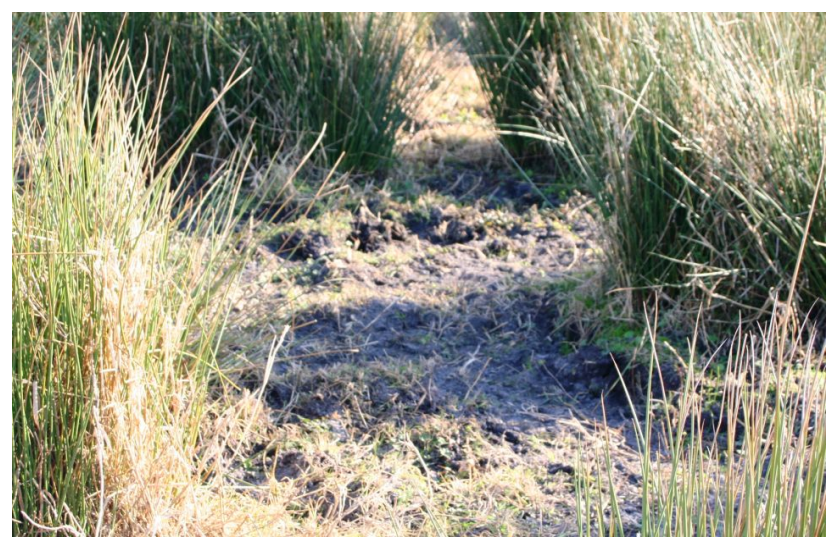

Figure 2. Dense soft-rush infestations result in overgrazing of desirable forage and excessive trampling around soft-rush clumps. Credits: Brent Sellers

The resulting bare-ground condition can, in turn, result in soil erosion and the movement of nutrients off of the pasture. For these reasons, it is desirable to remove soft rush in pastures where this plant is heavily infested.

1. This document is SS-AGR-325, one of a series of the Agronomy Department, Florida Cooperative Extension Service, Institute of Food and Agricultural Sciences, University of Florida. Original publication date, November 2009. Visit the EDIS Web site at http://edis.ifas.ufl.edu.

2. Brent Sellers, assistant professor, Agronomy Department, Range Cattle Research and Education Center (RCREC)--Ona, FL; Jason Ferrell, assistant professor, Agronomy Department, and Reyna Speckmann, assistant extension scientist, RCREC, Institute of Food and Agricultural Sciences, University of Florida.

The Institute of Food and Agricultural Sciences (IFAS) is an Equal Opportunity Institution authorized to provide research, educational information and other services only to individuals and institutions that function with non-discrimination with respect to race, creed, color, religion, age, disability, sex, sexual orientation, marital status, national origin, political opinions or affiliations. U.S. Department of Agriculture, Cooperative Extension Service, University of Florida, IFAS, Florida A. \& M. University Cooperative Extension Program, and Boards of County Commissioners Cooperating. Interim Dean Millie Ferrer. 


\section{Biology}

Soft rush is a clump-forming perennial that spreads by both short rhizomes and seed (Figure 3). Leaves are limited to small, brown scales near the base of the stems. Stems are cylindrical, pointed, and can reach up to of 5 feet in length. The inflorescence is a many-flowered, loosely clustered panicle, approximately 1 - 2 inches long (Figure 3 ). Seed production is extremely high with each shoot capable of producing 8,500 seeds per year.

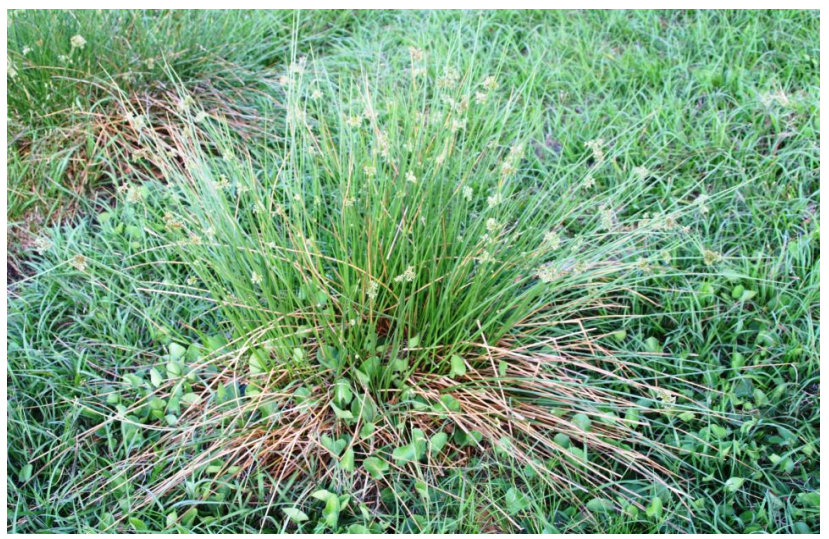

Figure 3. Soft rush typically flowers in the spring, April through June. Each plant is capable of producing at least 8,500 seeds per year. Credits: Brent Sellers

\section{Control}

Mowing is one tool that has been suggested for soft-rush management. However, mowing is usually only a temporary solution. Since standing water is typically present for weeks or months each year in areas of soft-rush infestation, mowing is usually limited to one operation per year. At this mowing interval, soft rush will usually regrow. Therefore, mowing for control is typically not a good option. Experiments conducted at the University of Florida's Range Cattle Research Center in Ona, FL, in 2006 and 2007 evaluated several herbicides for soft-rush control. Herbicides were applied to both clipped and non-clipped soft rush plants within one day of mowing. Products that contain 2,4-D provided the most effective control of soft rush (Figure 4).

\section{Forage Tolerance}

Limpograss is present in many seasonal wetlands where soft rush is commonly found. In the past, 2,4-D containing products (Weedmaster, Grazonnext, etc.) have not been recommended on limpograss pastures. However, our research has found that spring applications (when temperatures are cool) of 2,4-D cause little to no injury to limpograss. Therefore, we believe that 2,4-D can be applied in these seasonal wetlands during the dry period with little impact on forage production.

\section{Management}

Once soft rush is removed, take measures to prevent or limit the reestablishment of this weed. For six months following treatment in the 2006 and 2007 soft rush experiments, cattle did not graze in the area of the studies. This delay in returning cattle to the area for grazing allowed the forage to grow, resulting in less light penetration to the soil surface. The presence of desirable forage is extremely important as light is a requirement for germination of soft rush seeds.

Grazing pastures too soon following herbicide application to control soft rush can contribute to the light-dependent germination conditions that are optimum for soft rush seed. Regrowth of soft rush can result from premature grazing of forage in areas where soft rush has been controlled by herbicide. For this reason, it is recommend that grazing be limited during the first six months after herbicide application to soft rush.

\section{Recommendation}

Apply 2 qt/A of 2,4-D to soft-rush-infested pastures during the dry season, usually April to May. Limit grazing of the area for six months following herbicide application to prevent germination of soft-rush seed and subsequent regrowth. If grazing cannot be limited, plan to retreat the area with herbicide the following spring. 


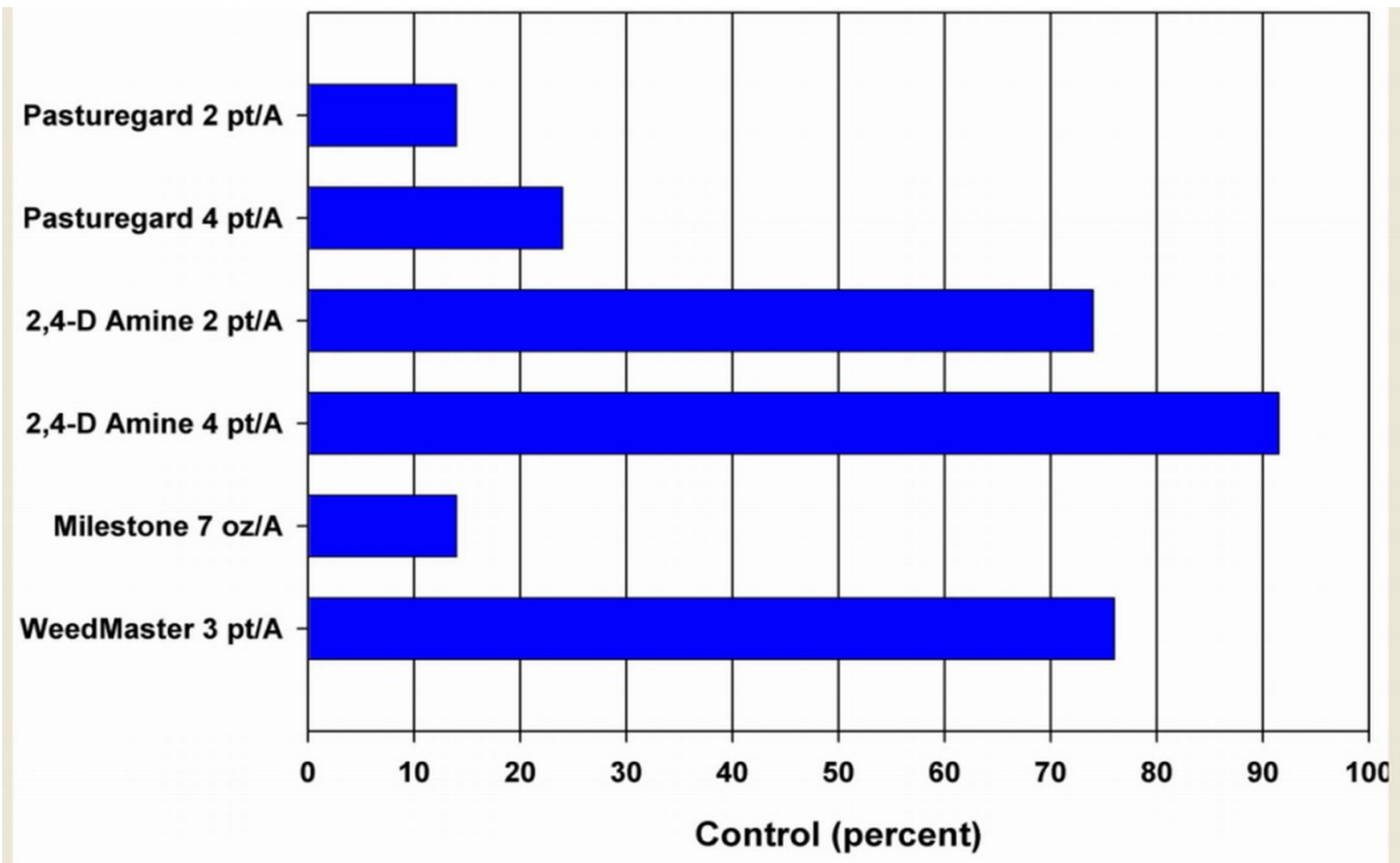

Figure 4. Control of soft rush with selected herbicides one year after treatment. 